\title{
Abelhas-sem-ferrão amazônicas defendem meliponários contra saques de outras abelhas
}

\author{
André Rodrigo $\mathrm{RECH}^{1}$, Mauricio Adu SCHWADE ${ }^{2 \mathrm{a}}$, Mayá Regina Müller SCHWADE ${ }^{2 \mathrm{~b}}$ \\ RESUMO: \\ Entre as abelhas eussociais, dois gêneros apresentam estratégia de vida cleptobiótica, obtendo recursos alimentares de ninhos \\ de outras abelhas ao invés de coletá-los em flores. Entre as espécies atacadas existe um gradiente de suscetibilidade ao roubo \\ variando desde espécies vulneráveis até altamente resistentes. Neste trabalho nós descrevemos um ataque de Lestrimelitta rufipes \\ a um ninho de Scaptotrigona sp. em um meliponário na Amazônia central (Amazonas, Brazil). O ninho atacado foi transferido \\ para um meliponário com espécies resistentes (Duckeola ghilianii e Melipona fulva) e as interaçóes foram descritas. As abelhas \\ resistentes contra-atacaram e afugentaram as ladras protegendo o ninho de Scaptotrigona sp.. A presença de comportamento \\ defensivo em gêneros náo proximamente relacionados sugere que ele tenha evoluído mais de uma vez entre os Meliponini. \\ Considerando o comportamento descrito, sugerimos a criaçáo de espécies nativas resistentes em meliponários de regiōes onde \\ elas forem nativas, devido ao potencial que elas tem na proteção.
}

PALAVRAS-CHAVE: cleptobiose, comportamento de defesa, Amazônia, abelha sem ferrão, Meliponini

\section{Amazonian stingless bees protect meliponaries against robber bees}

\begin{abstract}
:
Among eusocial bees, two genera evolved a cleptobiotic life strategy, stealing food resources from other bee nest instead of collecting it from flowers. Under natural conditions there is a gradient of strategies against robbing, from more susceptible to highly resistant species. In this work, we describe one attack of the robber bee Lestrimelitta rufipes to a nest of Scaptotrigona sp. in the Amazon Rain Forest (Amazonas, Brazil). The attacked nest was introduced in a beekeeping area with bees already known to be resistant to cleptobiosis. The resident bees (Duckeola ghilianii and Melipona fulva) counter-attacked the robber bees and successfully protect the Scaptotrigona sp. nest. The presence of the defensive behaviour in unrelated genera suggests it evolved many times in social bees. Based on the protective behaviour described here, we suggest that in order to reduce the damage caused by Lestrimelitta attacks in Amazonian beekeeping, a combination of defensive and non-resistant bees should be considered.
\end{abstract}

KEYWORDS: cleptobiosis, defensive behaviour, stingless bee, Amazonia, Meliponini

1 Universidade Estadual de Campinas (UNICAMP), Campus Zeferino Vaz, Instituto de Biologia (IB)/Departamento de Biologia Vegetal. Rua Monteiro Lobato 255. Caixa Posta 1691. CEP: 13083970. Campinas - São Paulo, Brasil e-mail: andrerodrigorech@gmail.com.

${ }^{2}$ Casa da Cultura do Urubui (CACUI), Rua Cupiuba, número 1. CEP: 69735-000. Presidente Figueiredo - Amazonas, Brasil, e-mail: a- mauadu@gmail.com,

b- mayaschwade@gmail.com. 
Eventos de saque entre colônias de abelhas eussociais, especialmente aqueles interespecíficos, não são raros na natureza, sobremaneira em períodos de escassez de recursos tróficos (Roubik 1989). No entanto, existem dois gêneros de abelhas sem ferrão (Meliponini: Lestrimelitta na região neotropical e Cleptotrigona na regiáo paleotropical) que, aparentemente, sobrevivem basicamente de pilhagem de mel, pólen, cerume e resinas, configurando-se parasitas saqueadores obrigatórios (Nogueira-Neto 1997).

Entre as espécies de Lestrimelitta Friese, 1903, a mais conhecida é Lestrimelitta limao (Smith, 1863), cujas operárias produzem e liberam durante os ataques um composto volátil a base de citral (odor característico de limão). Embora exista uma espécie com o epíteto específico "limao", a maioria das demais Lestrimelitta também produzem o volátil que dissipa a organização química das colônias de abelhas que elas atacam (Blum et al. 1970; Francke et al. 2000). As espécies que conseguem manter sua organização e comunicação sob a ação do citral dificilmente são atacadas (Pompeu e Silveira 2005).

$\mathrm{Na}$ regiáo amazônica, segundo relato de criadores de abelhas, os ataques de Lestrimelitta são frequentes, especialmente aos ninhos de Apis mellifera Linnaeus 1758. Por exemplo, em uma criação de abelhas em Presidente Figueiredo (AM), 120 ninhos de A. mellifera foram comprometidos por Lestrimelitta em 10 anos, sendo a principal causa isolada de perda de colônias (Pe. Egydio Schwade com. pes.). Embora em A. mellifera os ataques matem ou induzam o abandono da colônia, com relação às abelhas nativas é mais comum o estabelecimento de sequências de saques intermitentes (Santana et al. 2004). Parasitar colônias e saque-alas sem exaurí-las levando-as a morte, parece ser uma estratégia estável, uma vez que as Lestrimelitta spp. não forrageiam em flores e dependem exclusivamente dos produtos da pilhagem. Por exemplo, Sakagami e Laroca (1963) relatam um ninho de Plebeia emerina (Friese, 1900) que era atacado a cada dois meses em média, por anos consecutivos, sem que a colônia fosse morta durante ou em consequência desses ataques (Sakagami e Laroca 1963).

Na regiáo de Presidente Figueiredo - Amazonas, observaçōes prévias realizadas pelo segundo autor indicaram que Duckeola ghilianii (Spinola, 1853) defendia suas colônias e que os meliponários onde elas eram criadas pareciam menos suscetíveis à cleptobiose. Nesse sentido, o objetivo deste estudo foi documentar a resposta de $D$. ghilianii quando uma colônia de Scaptotrigona sp. sendo atacada por Lestrimelitta rufipes foi introduzida no meliponário onde elas estavam. O registro foi realizado no meliponário do sítio Bom Futuro (quilômetro 3 , ramal do Urubui), município de Presidente Figueiredo Amazonas (2 $02^{\prime} 03.83^{\prime \prime} \mathrm{S}$ e $\left.60^{\circ} 01^{\prime} 32.12^{\prime \prime} \mathrm{W}\right)$. A altitude média da região é de 122 metros em relação ao nível do mar e a área integra a porção sul do escudo das Guianas. A vegetação regional é de Floresta Tropical de Terra Firme, no entanto, no sítio de observação existe um sistema agroecológico com mais de 80 espécies de plantas cultivadas, alguns ninhos de A. mellifera e 30 de Meliponini (oito espécies).

O ninho de Scaptotrigona sp. utilizado nesse estudo estava há pelo menos um dia sob ataque de L. rufipes quando foi localizado em 14 de outubro de 2010. Ele foi então transferido experimentalmente para um meliponário com $D$. ghilianii e o comportamento das abelhas foi observado. As observaçóes foram realizadas nos dias 14 e 15 de outubro de 2010 , e os ninhos foram monitorados posteriormente para verificar como as abelhas se comportaram após o ataque.

No ninho observado, removemos o cerume depositado na entrada antes de perceber que a colônia de Scaptotrigona sp. ainda estava viva. Em seguida, abrimos a tampa da caixa e constatamos que as Lestrimelitta acessaram apenas uma pequena parte do ninho atacado. O cerume depositando na parte externa da entrada do ninho provinha de barreiras que as operárias de Scaptotrigona sp. construíram internamente para tentar impedir o avanço das saqueadoras. As operárias de $L$. rufipes retiraram cerume de dentro do ninho de Scaptotrigona sp. e o utilizaram para a "re-ornamentação" da entrada do ninho sob ataque (Bego et al. 1991; Sakagami et al. 1993). Acreditamos que essas marcas de cerume construídas por $L$. rufipes auxiliavam na localização e deslocamento das operárias ladras.

Sakagami et al. (1993) propuseram que as porçôes de cerume e resina depositadas pelas Lestrimelitta próximas à entrada pudessem contribuir para repelir forídeos (Diptera: Phoridae) e formigas que normalmente se aproximam quando ninhos de abelhas são manejados, mas essa hipótese nunca foi testada. De fato por todo o tempo havia forídeos movimentando-se sobre a caixa, porém, dificilmente entravam na mesma. Embora não estivessem defendendo a entrada de sua colônia, as operárias de D. ghilianii também perseguiam alguns forídeos e contribuíam para que a colônia de Scaptotrigona sp. náo fosse invadida por eles

Quando a caixa com Scaptotrigona sp. foi introduzida no meliponário em questão, as operárias de $D$. ghilianii se deslocaram até a entrada do ninho atacado e começaram a retirar as ladras (Figura $1 \mathrm{e}$ anexo 1 ). $\mathrm{O}$ comportamento de captura consistia em uma "provocação" por parte das $D$. ghilianii que levava as $L$. rufipes a saírem do tubo de entrada, sendo então capturadas e mortas. A "provocação" consistia em um comportamento estereotipado, na forma de dança, durante a qual as abelhas permaneciam com as asas abertas. Após capturar uma ladra, a operária de D. ghilianii a manipulava até que conseguisse uma posição na qual fosse possível mordê-la. As operárias de D. ghilianii revezavam-se na tentativa e matar as ladras, cada ladra foi atacada em média três vezes, sempre por indivíduos diferentes. Cada investida sobre uma ladra 


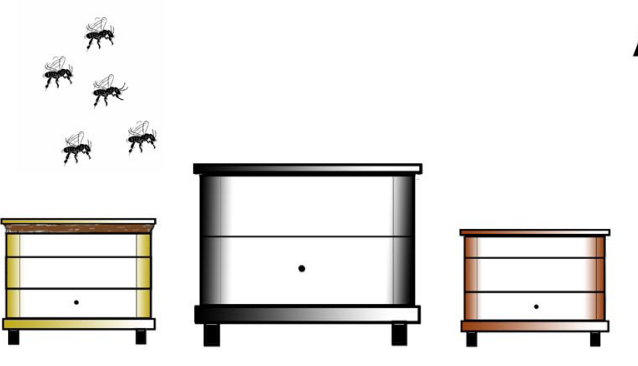

A
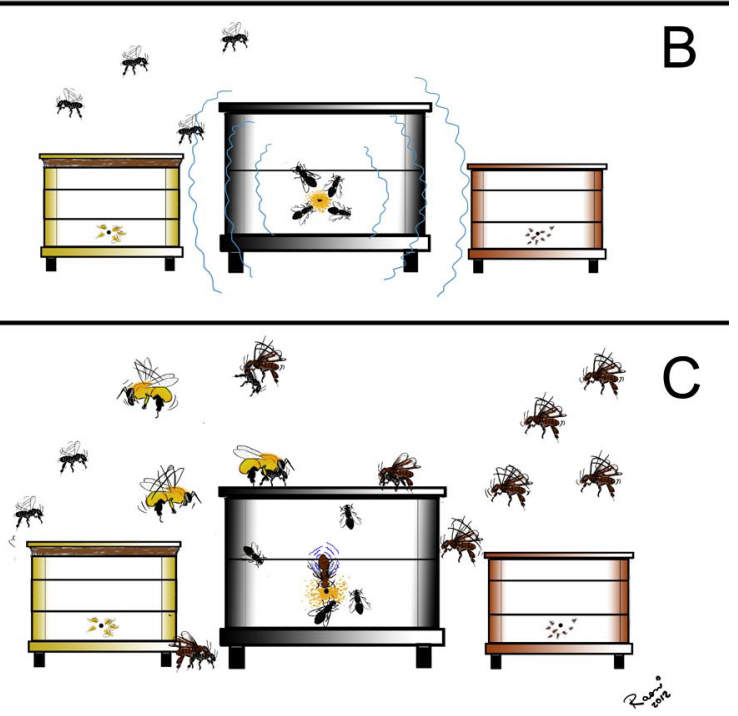

Figura 1 - Representação do processo de ataque e defesa de colônias de abelhas eussociais em Presidente Figueiredo - Amazônia. A. Operárias de Lestrimellita rufipes reencontrando o ninho de Scaptotrigona sp. sob ataque (ao centro) transferido para um meliponário com espécies resistentes $(D$. ghilianii à direita e $M$. fulva à esquerda). B. Modificação da entrada do ninho atacado pelas ladras e liberação de odor cítrico. C. Contra-ataque das abelhas resistentes. Um vídeo mostrando o processo de ataque e defesa da colônia está disponível no endereço: http://www.scielo.br/img/revistas/aa/v43n3/ videos/n3a16video.wmv

durou em média 7,3 s $( \pm 5,5 \mathrm{~s}, \mathrm{n}=21)$. Em vários ataques indivíduos de $L$. rufipes permaneciam agarrados às pernas das operárias de $D$. ghilianii mesmo depois de mortos.

Apesar de o ninho atacado ter sido deslocado 30 metros do local onde o ataque começou, novos grupos de L. rufipes, compostos cada um por no mínimo 50 abelhas, localizaramno e continuaram chegando acompanhados de forte odor cítrico (Figura 1). Imediatamente após a chegada seguiu-se um alvoroço das $D$. ghilianii, que saíram de seu ninho e se posicionaram próximas à entrada do ninho de Scaptotrigona sp., capturando as ladras antes que essas pudessem pousar (Figura 1). O grupo de operárias de D. ghilianii defendendo o ninho de Scaptotrigona variou entre 10 e 50 indivíduos dependendo da abundância de ladras.

As operárias de D. ghilianii capturavam as ladras ainda em voo ou logo que pousavam na superfície da caixa. Em ataques a outras colônias observados anteriormente, as $L$. rufipes também chegavam em grupos e pousavam em formação circular. Nesse tipo de formaçáo normalmente os indivíduos da borda do círculo permaneciam com a cabeça voltada para fora (M. A. Schwade, observaçôes pessoais). Porém, o comportamento de defesa de D. ghilianii impediu que as ladras se agrupassem, sendo atacadas quando estavam sozinhas ou no máximo em trios. Esse comportamento demonstra que D. ghilianii é efetivamente eficiente no controle das ladras, diferente dos casos anteriormente descritos na literatura, nos quais, o processo de defesa sempre comprometia severamente uma quantidade grande de operárias machucadas ou igualmente mortas durante a defesa. No caso descrito náo foram observadas mortes de D. ghilianii enquanto atuavam na defesa da colônia vizinha.

No decorrer das observaçóes apareceram indivíduos de Melipona fulva Lepeletier, 1836 de outro ninho próximo, cujo comportamento também foi registrado. As operárias de M. fulva foram menos abundantes (em média 5-7 indivíduos) e também menos efetivas que as de $D$. ghilianii no controle das ladras. Nesse sentido, as operárias de $M$. fulva predominantemente retiraram operárias mortas de $L$. rufipes. Embora sempre se evitassem mutuamente, foram observadas poucas agressóes entre $M$. fulva e $D$. ghilianii e nenhuma morte decorrente de confronto entre elas. A capacidade de reagir ao odor cítrico foi constatada quando algumas abelhas ladras foram esmagadas já mortas e apresentadas nas entradas dos ninhos às operárias de $D$. ghilianii e $M$. fulva que imediatamente alvoroçavam-se e deslocavam-se para o local de onde o odor era liberado.

A análise superficial da relação documentada pode induzir o pensamento de que exista um altruísmo interespecífico entre as espécies de abelha estudadas, mecanismo ainda não descrito e aparentemente insustentável do ponto de vista evolutivo (Freeman e Herron 2009). No entanto, nos parece mais plausível pensar que ocorre um comportamento eficiente de defesa de seus ninhos por parte de D. ghilianii e $M$. fulva, e que estas rapidamente reconheçam e respondam ao odor cítrico produzido por L. rufipes. Além disso, a presença de saqueadoras na vizinhança representa uma ameaça direta às demais colônias do local, e provavelmente as abelhas "defensoras" estivessem apenas defendendo seus próprios ninhos. Vale ressaltar que todo o processo descrito ocorreu em um meliponário, ou seja, a distribuição espacial das espécies não representa um cenário no qual as relaçôes interespecíficas evoluem naturalmente.

As espécies de Meliponini dos gêneros Scaptotrigona, Nannotrigona e Plebeia, estão entre as abelhas mais susceptíveis a eventos de saque por abelhas ladras (Bego et al. 1991; Sakagami et al. 1993). O gênero Scaptotrigona compreende espécies que apresentam ninhos muito populosos, os maiores dentre abelhas sem ferrão, o que demanda um grande e constante suprimento de recursos alimentares 
(Michener 1974). Essa característica associada à simpatria com Lestrimelitta e à vulnerabilidade das espécies ao odor de citral levaram Sakagami et al. (1993) a propor um cenário evolutivo no qual abelhas desses gêneros fossem preferidas por abelhas ladras.

Com relação à defesa, espécies resistentes aos ataques de L. limao já foram descritas anteriormente nos gêneros Tetragonisca e Melipona, com registro inclusive de defesa de ninhos próximos (Sakagami et al. 1993). Quando apenas Tetragonisca angustula era tida como uma espécie resistente, a resistência foi explicada com base na simpatria das espécies ( $T$. angustula e L. limao) e, portanto, na longa história evolutiva compartilhada dessas duas espécies (Wittmann et al. 1990). No entanto, o presente trabalho e o realizado com $M$. rufiventris Lepeletier, 1836 (Pompeu e Silveira 2005), mostram que a resistência ocorre em diferentes gêneros de Meliponini. Porém nesses gêneros ocorrem também espécies suscetíveis a ataques, como por exemplo, M. quadrifasciata (Sakagami et al. 1993). O fato de espécies resistentes pertencerem a gêneros não proximamente relacionados (Tetragonisca, Melipona e Duckeola) e o fato da característica não ser sinapomórfica para um clado sugere que o comportamento tenha evoluído mais de uma vez.

No caso de T. angustula, Grüter et al. (2012) demonstraram a existência de diferenciação morfológica entre as operárias, sendo as abelhas maiores as responsáveis pela defesa da colônia. A resistência aos saques seria assim explicada pela existência, em espécies resistentes, de um grupo diferenciado de operárias responsáveis pela defesa da colônia. Dada à eficiência com que operárias de D. ghilliani atacam abelhas ladras, a hipótese de especialização em atividades de defesa parece plausível, embora careça de ser testada. No caso de haver tal especializaçáo náo seria o comportamento de defesa que evoluiu mais de uma vez, mas a existência de uma "casta" de operárias especializadas em defender a colônia e morfologicamente hábeis a fazê-lo.

Aparentemente, o fato de uma espécie ser capaz de reconhecer o odor de citral, mas não se desestabilizar sob seu efeito, parece somar ao mecanismo de resistência (Blum et al. 1970; Pompeu e Silveira 2005). No entanto, a capacidade de reagir e impedir um ataque aparentemente vai além da relação com citral. As colônias precisam ser populosas (número de operárias) e saudáveis, ter estratégias de enfrentamento, bem como, apresentar características biológicas específicas, como no caso de $M$. rufiventris, $M$. fulva e D. ghilianii. Além disso, caso seja confirmada a existência de "castas" de defesa nas outras espécies resistentes, também esse pode ser um fator chave para a resistência.

As abelhas da espécie D. ghilianii apresentam boas características para a criaçáo racional por sua relativamente baixa agressividade ao manejo, boa produção de mel, rusticidade e resistência ao ataque de Lestrimelitta. Além disso, com base nas observaçóes realizadas, D. ghilianii apresenta potencialidade na proteção de colônias de outras espécies. Já foram observadas reaçôes de $D$. ghilianii contra ataques de L. rufipes em ninhos de outras espécies que estavam até 1,5 $\mathrm{m}$ de distância (Egydio Schwade, com. pess.). Isso representa um importante raio de proteção, visto que náo foi observado comportamento agonístico entre D. ghilianii e as demais espécies, mesmo quando os ninhos estavam afastados apenas $50 \mathrm{~cm}$ (entre elas Scaptotrigona sp., M. fulva, Frieseomelitta flavicornis (Fabricius, 1798) e A. mellifera). Nessa perspectiva, sugerimos que a criação racional de abelhas sem ferrão consorciada com D. ghilianii deve ser testada nas regiôes onde essa espécie ocorre naturalmente.

\section{AGRADECIMENTOS}

Dedicamos esse trabalho a memória de Doroti Müller Schwade por inspirar o conhecimento da Amazônia com ética e respeito à vida. Agradecemos à Dra. Silvia R. M. Pedro pela identificação das espécies de abelha e a Anna Abrahão, Leonardo Ré Jorge, Marcelo Moro e Vinicius Duartina pela leitura criteriosa e sugestôes na primeira versão do manuscrito. Agradecemos também aos revisores pelas importantes consideraçôes e a Fapesp (Proc. 2009/54.491-0) e CNPq pelo auxílio financeiro.

\section{BIBLIOGRAFIA CITADA}

Bego, L. R.; Zucchi, R.; Mateus S. 1991. Notas sobre a estratégia alimentar (cleptobiose) de Lestrimelitta limao Smith (Hymenoptera, Apidae, Meliponinae). Naturalia, 16: 119-127.

Blum, M. S.; Crewe, R. M.; Kerr, W. E.; Keith L. E.; Garrison, A. W. E; Walker, M. M. 1970. Citral in stingless bees: isolation and functions in trail-laying and robbing. Journal of Insect Physiology, 16: $1637-1648$

Francke, W.; Lubke, G.; Schoder, W.; Reckziegel, A.; ImperatrizFonseca, V.; Kleinert, A.; Engels, E.; Hartfelder, K.; Radtke, R.; Engels, W. 2000. Identification of oxygen containing volatiles in cephalic secretions of workers of Brazilian stingless bees. Brazilian Journal of Chemistry Society, 11(6): 562-571.

Freeman, S.; Herron, J. C. 2009. Análise Evolutiva. 4a. edição, editora Artmed. 848p.

Grüter, C.; Menezes, C.; Imperatriz-Fonseca, V. L.; Ratnieks, F. L. W. 2012. A morphologically specialized soldier caste improves colony defense in a neotropical eusocial bee. Proceedings of the National Academy of Sciences, 109 (4): 1182-1186.

Michener, C. D. 1974. The social behavior of the bees: A comparative study. Harvard University Press, Cambridge, Massachusetts, USA. xii + 404 pp.

Nogueira-Neto, P. 1997. Vida e criação de abelhas indígenas sem ferrão. Nogueirapis, São Paulo. 446 pp.

Pompeu, M. S.; Silveira, F. A. 2005. Reaction of Melipona rufiventris Lepeletier to citral and against an attack by the cleptobiotic bee 
Lestrimelitta limao (Smith) (Hymenoptera: Apidae: Meliponina). Brazilian Journal of Biology 65(1): 189-191.

Roubik, D. W. 1989. Ecology and natural history of tropical bees. Cambridge University Press, New York, USA. 516 pp.

Sakagami, S. F. E.; Laroca, S. 1963. Additional observations on the habits of the cleptobiotic stingless bees, the genus Lestrimelitta Friese (Hymenoptera, Apoidea). Journal of the Faculty of Science, 15: 319-339.
Sakagami, S. F.; Roubik, D. W. E.; Zucchi, R. 1993. Ethology of the robber stingless bee, Lestrimelitta limao (Hymenoptera, Apidae). Sociobiology, 21: 237-277.

Santana W. C.; Freitas G. S.; Akatsu I. P.; Espencer A. S. E. 2004. Abelha Iratim (Lestrimelitta limao Smith: Apidae, Meliponinae), realmente é danosa às populaçóes de abelhas? Necessita ser eliminada? Mensagem Doce, 78.

Wittmann, D.; Radtke, R.; Zeil, J.; Lubke, G.; Francke, W. 1990. Robber bees (Lestrimelitta limao) and their host chemical and visual cues in nest defense by Trigona (Tetragonisca) angustula (Apidae: Meliponinae). Journal of Chemical Ecology 16(2): 631-641.

Recebido em: 03/04/2012

Aceito em: 10/10/2012 
